\title{
Onium Salts of Sulfur-Containing Oxyanions Resulting from Reaction of Sulfur(IV) Oxide with Aqueous Solutions of 1,2-Diamines and Morpholine
}

\author{
R. E. Khoma ${ }^{a, b}$, *, V. O. Gel'mbol'dt ${ }^{c}$, A. A. Ennan ${ }^{a}$, V. N. Baumer ${ }^{d}$, \\ A. N. Puzan ${ }^{d}$, T. V. Koksharova ${ }^{b}$, and A. V. Mazepa ${ }^{e}$ \\ a Physicochemical Institute for Environment and Human Protection, \\ National Academy of Sciences of Ukraine, Odessa, 65082 Ukraine \\ ${ }^{b}$ Odessa National University, Odessa, 65082 Ukraine \\ ${ }^{c}$ Odessa National Medical University, Odessa, 65082 Ukraine \\ ${ }^{d}$ Institute of Single Crystals, National Academy of Sciences of Ukraine, Kharkov, 61001 Ukraine \\ ${ }^{e}$ Bogatskii Physicochemical Institute, National Academy of Sciences of Ukraine, Odessa, 65080 Ukraine \\ *e-mail:rek@onu.edu.ua \\ Received July 14, 2016
}

\begin{abstract}
Reaction products have been isolated from $\mathrm{SO}_{2}-\mathrm{L}-\mathrm{H}_{2} \mathrm{O}-\mathrm{O}_{2}$ systems $(\mathrm{L}=$ ethylenediamine, $N, N, N^{\prime}, N^{\prime}$-tetramethylethylenediamine, piperazine, and morpholine) as onium salts $\left[\mathrm{H}_{3} \mathrm{NCH}_{2} \mathrm{CH}_{2} \mathrm{NH}_{3}\right] \mathrm{SO}_{4}, \quad\left[\left(\mathrm{CH}_{3}\right)_{2} \mathrm{NHCH}_{2} \mathrm{CH}_{2} \mathrm{NH}\left(\mathrm{CH}_{3}\right)_{2}\right] \mathrm{SO}_{4}, \quad\left[\left(\mathrm{CH}_{3}\right)_{2} \mathrm{NHCH}_{2} \mathrm{CH}_{2} \mathrm{NH}\left(\mathrm{CH}_{3}\right)_{2}\right] \mathrm{S}_{2} \mathrm{O}_{6}$. $\mathrm{H}_{2} \mathrm{O},\left[\mathrm{C}_{4} \mathrm{H}_{8} \mathrm{~N}_{2} \mathrm{H}_{4}\right] \mathrm{SO}_{3} \cdot \mathrm{H}_{2} \mathrm{O},\left[\mathrm{C}_{4} \mathrm{H}_{8} \mathrm{~N}_{2} \mathrm{H}_{4}\right] \mathrm{S}_{2} \mathrm{O}_{6},\left[\mathrm{C}_{4} \mathrm{H}_{8} \mathrm{~N}_{2} \mathrm{H}_{4}\right] \mathrm{SO}_{4} \cdot \mathrm{H}_{2} \mathrm{O},\left[\mathrm{O}\left(\mathrm{C}_{2} \mathrm{H}_{4}\right)_{2} \mathrm{NH}_{2}\right]_{2} \mathrm{SO}_{4} \cdot \mathrm{H}_{2} \mathrm{O}$. The prepared compounds have been characterized by $\mathrm{X}$-ray diffraction analysis, $\mathrm{X}$-ray powder diffraction, IR and mass spectroscopy.
\end{abstract}

DOI: $10.1134 / \mathrm{S} 0036023617060109$

Ethylenediamine (EDA), $N, N, N^{\prime}, N^{\prime}$-tetramethylethylenediamine (TMEDA), piperazine (PP), and its structural analog morpholine (MP) exhibit properties of mono- and diacidic bases producing salts with mineral and organic acids [1-8]. The interest in this group of compounds is associated with the possibility of their practical application.

In particular, ethylenediammonium salts are promising materials for nonlinear optics [3], they show proton and dielectric conductance [4]. Ethylenediammonium dicarboxylates exhibit antimicrobial and fungicide activity [8], PP and its salts are used in medicine and veterinary as anthelmintic remedies [1]. In this paper, we describe method of synthesis, structural study, spectral properties, and thermal stability of products resulting from the reaction of $\mathrm{SO}_{2}$ with aqueous solutions of 1,2-diamines and morpholine in the presence of air oxygen.

\section{EXPERIMENTAL}

Ethylenediammonium sulfate (I). A solution of EDA monohydrate $(0.10 \mathrm{~mol})$ in $10 \mathrm{~mL}$ of water was placed into a thermostatted cell, gaseous $\mathrm{SO}_{2}$ was bubbled through the solution at $0^{\circ} \mathrm{C}$ at a rate $50 \mathrm{~mL} / \mathrm{min}$ until $\mathrm{pH}<1.0$. The solution with precipitate was subjected to isothermal evaporation at ambient temperature in air until complete removal of water. The isolated white crystalline product I (15.61 g, yield toward EDA 98.7\%; mp $225-227^{\circ} \mathrm{C}$ ) was used without additional purification.

MS: $\left[\mathrm{SO}_{2}\right]^{+}(m / z=64, I=42 \%) ;\left[\mathrm{M}_{\mathrm{L}}\right]^{+}(m / z=60$, $I=5 \%) ;\left[\mathrm{M}_{\mathrm{L}}-\mathrm{H}\right]^{+}(m / z=59, I=5 \%) ;[\mathrm{SO}]^{+}(\mathrm{m} / z=$ $48, I=19 \%) ;\left[\mathrm{CH}_{3} \mathrm{CH}=\mathrm{NH}_{2}\right]^{+}(m / z=44, I=5 \%)$; $m / z=43, I=10 \% ; m / z=42, I=8 \% ;\left[\mathrm{CH}_{2}=\mathrm{NH}_{2}\right]^{+}$ $(m / z=30, I=100 \%)$.

For $\mathrm{C}_{2} \mathrm{H}_{10} \mathrm{~N}_{2} \mathrm{O}_{4} \mathrm{~S}$ anal. calcd. (\%): C, 15.19; $\mathrm{H}$, 6.37; N, 17.71; S, 20.27. $M$ 158.18. Found (\%): C, 15.07; H, 6.23; N, 17.12; S, 20.64.

A mixture of $N, N, N^{\prime}, N^{\prime}$-tetramethylethylenediammonium sulfate dihydrate (IIa) and $N, N, N^{\prime}, N^{\prime}-$ tetramethylethylenediammonium dithionate monohydrate (IIb). Similar procedure for a TMEDA aqueous solution $\left(0.05 \mathrm{~mol}\right.$ of the amine in $10 \mathrm{~mL}$ of $\left.\mathrm{H}_{2} \mathrm{O}\right)$ gave rise to $6.43 \mathrm{~g}$ of a yellow-brown mixture of crystalline products IIa and IIb.

Anal. calcd. (\%): C, 25.62; H, 7.88; N, 9.96; S, 16.91. Found (\%): C, 25.74; H, 7.97; N, 9.88; S, 16.85.

A mixture of piperazinium sulfite (IIIa), piperazinium dithionate (IIIb), and piperazinium sulfate monohydrate (IIIc). Similar procedure for an aqueous solu- 
tion of PP octahydrate $(0.05 \mathrm{~mol}$ of the amine in $10 \mathrm{~mL}$ of $\mathrm{H}_{2} \mathrm{O}$ ) resulted in $10.66 \mathrm{~g}$ of a white mixture of crystalline products IIIa, IIIb, and IIIc.

MS: $\left[\mathrm{M}_{\mathrm{L}}\right]^{+}(m / z=86, I=34 \%) ;\left[\mathrm{M}_{\mathrm{L}}-\mathrm{H}\right]^{+}(m / z=$ $85, I=28 \%) ; m / z=80, I=28 \%$; $\left[\mathrm{SO}_{2}\right]^{+}(m / z=64$, $I=24 \%) ;\left[\mathrm{CH}_{2} \mathrm{CH}_{2} \mathrm{NH}=\mathrm{CH}_{2}\right]^{+}(m / z=57, I=30 \%)$; $\left[\mathrm{CH}_{2}=\mathrm{CHNH}=\mathrm{CH}_{2}\right]^{+}(m / z=56, I=31 \%) ;[\mathrm{SO}]^{+}$ $(m / z=48, I=17 \%) ;\left[\mathrm{CH}_{2}=\mathrm{NHCH}_{3}\right]^{+}(\mathrm{m} / z=44, I=$ $100 \%) ;\left[\mathrm{CH}_{2}=\mathrm{NH}_{2}\right]^{+}(m / z=30, I=31 \%)$.

Anal. calcd. (\%): C, 24.90; H, 7.24; N, 14.51; S, 17.75. Found (\%): C, 24.98; H, 7.38; N, 14.43; S, 17.67 .

Morpholinium sulfate monohydrate (IV). Similar procedure for an aqueous solution of MP $(0.10 \mathrm{~mol}$ of the amine in $10 \mathrm{~mL}$ of $\mathrm{H}_{2} \mathrm{O}$ ) resulted in $12.62 \mathrm{~g}$ of white crystalline product IV (yield $87.0 \%$ toward MP, mp 20-22 ${ }^{\circ} \mathrm{C}$ ).

MS: $\left[\mathrm{M}_{\mathrm{L}}\right]^{+}(m / z=87, I=66 \%) ;\left[\mathrm{M}_{\mathrm{L}}-\mathrm{H}\right]^{+}(m / z=$ $86, I=27 \%)$; $\left[\mathrm{SO}_{2}\right]^{+}(m / z=64, I=27 \%)$; $\left[\mathrm{M}_{\mathrm{L}}-\right.$ $\left.\mathrm{CH}_{2} \mathrm{O}\right]^{+}(m / z=57, I=100 \%) ;\left[\mathrm{M}_{\mathrm{L}}-\mathrm{CH}_{2} \mathrm{O}-\mathrm{H}\right]^{+}$ $(m / z=56, I=35 \%)$; $[\mathrm{SO}]^{+}(\mathrm{m} / z=48, I=32 \%)$; $\left[\mathrm{CH}_{2}=\mathrm{NH}_{2}\right]^{+}(m / z=30, I=41 \%)$.

For $\mathrm{C}_{8} \mathrm{H}_{22} \mathrm{~N}_{2} \mathrm{O}_{7} \mathrm{~S}$ anal. calcd. (\%): C, 33.10; $\mathrm{H}$, 7.64; N, 9.65; S, 38.57; $M$ 290.34. Found (\%): C, $29.76 ; \mathrm{H}, 7.51 ; \mathrm{N}, 9.53 ; \mathrm{S}, 39.03$.

Analysis for carbon, hydrogen, and nitrogen content was carried out on a CHN analyzer, sulfur was determined by the Schoniger technique [9]. X-ray diffraction study of compounds II-IV was performed on an Oxford Diffraction Xcalibur-3 diffractometer $\left(\mathrm{Mo} K_{\alpha}\right.$ radiation, graphite monochromator, Sapphire-3 CCD detector). The structure was solved and refined using SHELX-97 software package [10]. Hydrogen atoms were located from a difference-Fourier map and refined using the Riding model for methyl and methylene groups. Hydrogen atoms involved in hydrogen bonding (HB) were refined in isotropic approximation. X-ray powder diffraction (XRD) was accomplished on a Siemens D500 powder diffractometer (Bragg-Bretano geometry, $\mathrm{Cu} K_{\alpha}$ radiation, Ni filter). IR spectra were recorded on a PerkinElmer Spectrum BX II FT-IR System spectrophotometer in $4000-350 \mathrm{~cm}^{-1}$ region as $\mathrm{KBr}$ pellets, mass spectra were obtained on a MX-1321 instrument (direct inlet into source, ionizing voltage $70 \mathrm{eV}$ ).

The main crystallographic data and refinement results for structures IIa-IV are presented in Table 1. Atom coordinates, structural factors and all refinement results were deposited in the Cambridge Crystallographic Data Center (Table 1). Geometrical characteristics of hydrogen bonds observed in structures $\mathbf{I I b}-$ IV are given in Table 2.

\section{RESULTS AND DISCUSSION}

The mass spectrum of compound I displays fragmentation typical for $1-n$-alkylamines [11] resulting in formation of $\left[\mathrm{CH}_{2}=\mathrm{NH}_{2}\right]^{+}$ion with peak of the maximal intensity. Piperazine fragmentation products in the mass spectrum of mixture of its onium salts IIIa, IIIb, and IIIc agree well with the tabulated mass spectrum of PP [11]. Similar agreement is observed for MP.

According to X-ray diffraction study, compound I is ethylenediammonium sulfate structurally characterized previously [2]. TMEDA produces a mixture of onium sulfate IIa and dithionate dihydrate IIb. Structure IIa was also described in the literature [12] and is not discussed below. In structure IIb (Fig. 1), cation and anion occupy the centers of symmetry while water molecule is in a general position. Bond distances and valence angles have common values for similar compounds. Packing in crystal causes formation of 2D system of hydrogen bonds (Table 2) producing layers in (001) planes. Rietveld refinement for powder diffraction patterns of reaction product showed almost equal content of compounds IIa and IIb in powder (IIa : IIlb = $46: 54)$.

The reaction of $\mathrm{SO}_{2}$ with aqueous solution of $\mathrm{PP}$ leads to formation of three compounds: sulfite monohydrate IIIa, dithionate IIIb, and sulfate monohydrate IIIc. The structure of compound IIIa (Fig 2) includes both cations in the centers of symmetry. Bond distances and valence angles are common. The compound forms a 3D system of hydrogen bonds in crystal (Table 2). Both basis molecules in structure IIIb (Fig. 3) are in general position. Dithionate ions in crystal are located in (100) coordinate planes, cation layers are located between them. A branched 3D system of hydrogen bonds is formed in the structure (Table 2). Structure IIIc includes two cations located in the centers of symmetry (Fig. 4). Crystal contains cation layers in (001) planes, while anions and water molecules are located in cavities between the layers. The system of hydrogen bonds in structure IIIc is three-dimensional. To determine compound ratio in reaction product, we calculated powder diffractogram of the latter by the Rietveld method using found by us structure models IIIa, IIIb, and IIIc (Fig. 5). The found composition is as follows (wt \%): IIIa, 74.8; IIIb, 8.8; IIIc, 16.4. Figure 5 shows that the reaction product contains no other substances.

The reaction of $\mathrm{SO}_{2}$ with aqueous solution of MP leads to only one compound, morpholinium (IV) sulfate monohydrate, whose structure is shown in Fig. 6. Like in compound IIIc, the structure IV includes anions and water molecules between cation layers producing a $3 \mathrm{D}$ system of hydrogen bonds.

The data of IR spectroscopy (Table 3) indicate that reaction product of PP contains sulfite ion, whereas other obtained products contain sulfate ions. The IR spectra of products obtained from TMEDA and PP exhibit also absorption bands of dithionate anions. 


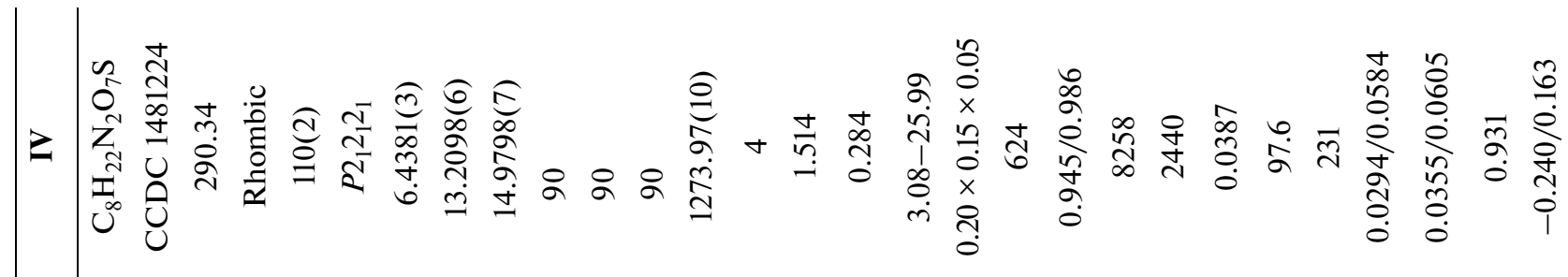

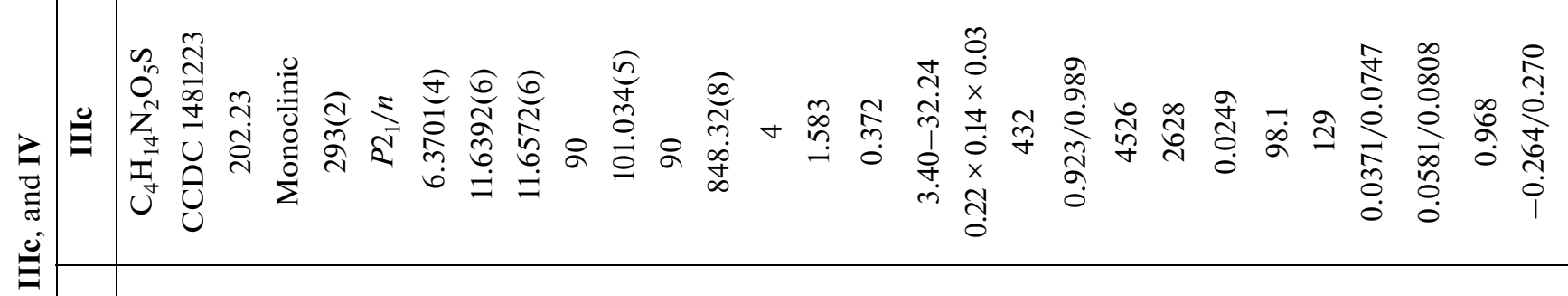

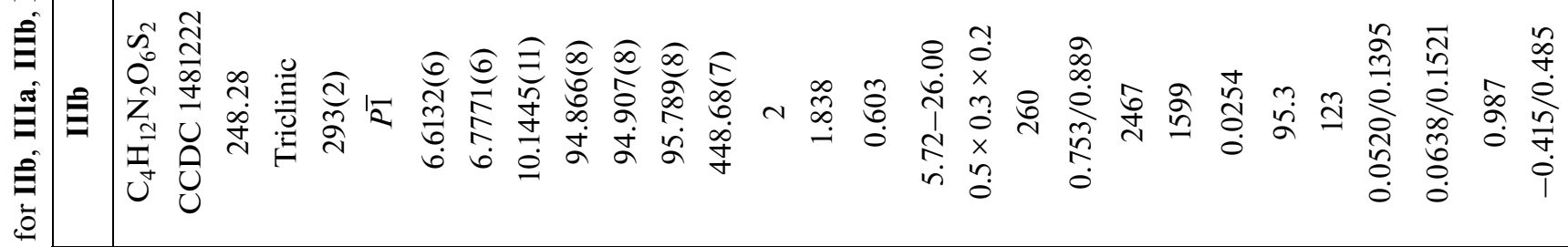

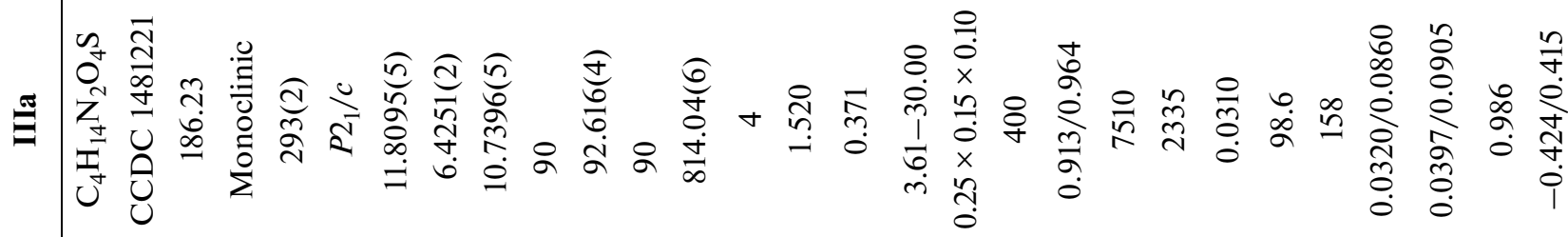

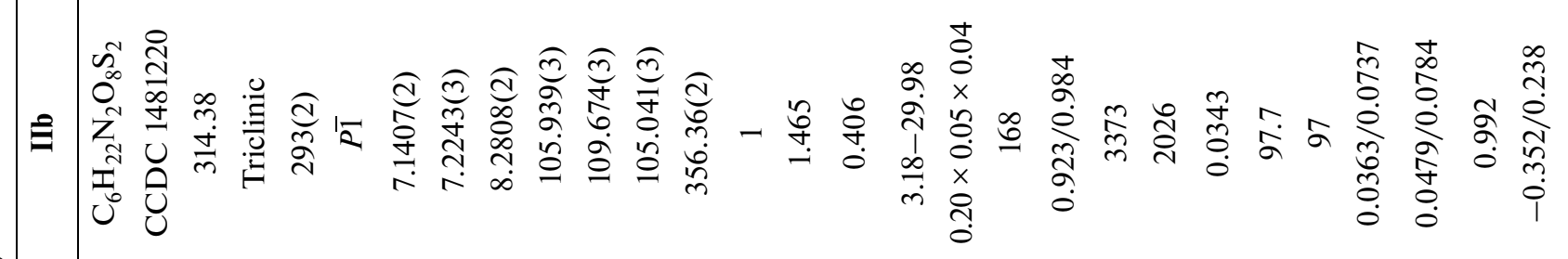

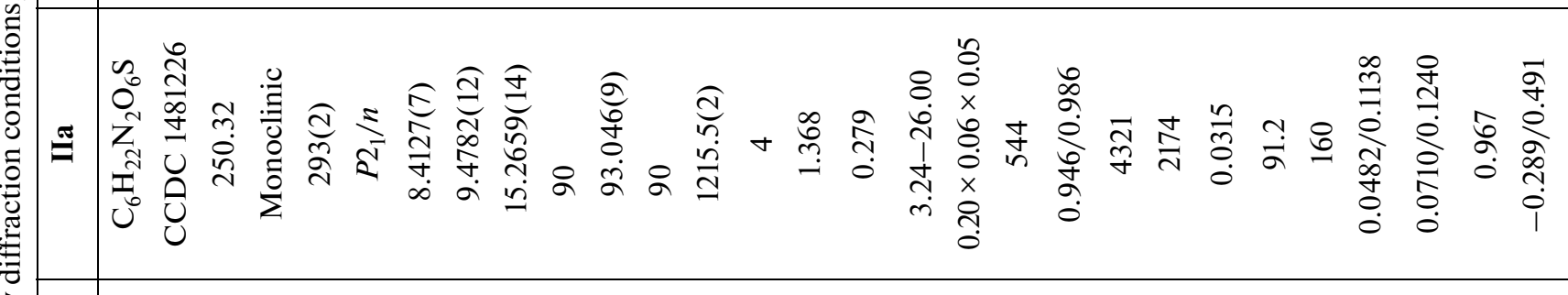

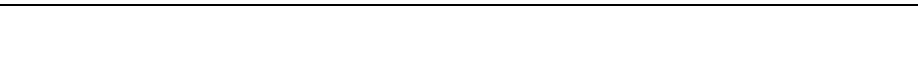


Table 2. Geometrical characteristics of hydrogen bonds in structures IIb, IIIa, IIIb, IIIc, and IV

\begin{tabular}{|c|c|c|c|c|c|}
\hline \multirow{2}{*}{ Contact D-H $\cdots$ A } & \multicolumn{3}{|c|}{ Distance, $\AA$} & \multirow{2}{*}{$\begin{array}{c}\text { DHA angle, } \\
\text { deg }\end{array}$} & \multirow{2}{*}{ Transformation for atom A } \\
\hline & $d(\mathrm{D}-\mathrm{H})$ & $d(\mathrm{H} \cdots \mathrm{A})$ & $d(\mathrm{D} \cdots \mathrm{A})$ & & \\
\hline \multicolumn{6}{|c|}{ IIb } \\
\hline $\mathrm{N}(1)-\mathrm{H}(1) \cdots \mathrm{O}(4)$ & $0.819(14)$ & $1.983(14)$ & $2.7614(14)$ & $158.5(12)$ & \\
\hline $\mathrm{N}(1)-\mathrm{H}(1) \cdots \mathrm{O}(3)$ & $0.819(14)$ & $2.654(12)$ & $3.1033(12)$ & $116.1(11)$ & $x+1, y, z$ \\
\hline $\mathrm{O}(4)-\mathrm{H}(4 \mathrm{~A}) \cdots \mathrm{O}(2)$ & $0.850(18)$ & $1.927(18)$ & $2.7645(13)$ & $168.4(13)$ & \\
\hline $\mathrm{O}(4)-\mathrm{H}(4 \mathrm{~B}) \cdots \mathrm{O}(1)$ & $0.804(15)$ & $2.050(15)$ & $2.8520(12)$ & $174.9(17)$ & $-x+2,-y+2,-z+1$ \\
\hline \multicolumn{6}{|c|}{ IIIa } \\
\hline $\mathrm{O}(4)-\mathrm{H}(4 \mathrm{~A}) \cdots \mathrm{O}(3)$ & $0.86(2)$ & $2.00(2)$ & $2.8513(16)$ & $178(2)$ & $x, y-1, z$ \\
\hline $\mathrm{O}(4)-\mathrm{H}(4 \mathrm{~B}) \cdots \mathrm{O}(2)$ & $0.78(2)$ & $2.05(2)$ & $2.8174(16)$ & $167(2)$ & \\
\hline $\mathrm{N}(1)-\mathrm{H}(1 \mathrm{~A}) \cdots \mathrm{O}(1)$ & $0.881(15)$ & $1.870(16)$ & $2.7309(13)$ & $165.0(14)$ & \\
\hline $\mathrm{N}(1)-\mathrm{H}(1 \mathrm{~B}) \cdots \mathrm{O}(1)$ & $0.859(17)$ & $1.852(17)$ & $2.7096(13)$ & $175.7(15)$ & $-x+1, y+1 / 2,-z+3 / 2$ \\
\hline $\mathrm{N}(2)-\mathrm{H}(2 \mathrm{~A}) \cdots \mathrm{O}(3)$ & $0.870(16)$ & $1.844(17)$ & $2.7037(14)$ & $169.1(16)$ & $-x+1,-y,-z+1$ \\
\hline $\mathrm{N}(2)-\mathrm{H}(2 \mathrm{~B}) \cdots \mathrm{O}(2)$ & $0.929(18)$ & $1.805(18)$ & $2.6831(13)$ & $156.6(16)$ & $-x+1, y+1 / 2,-z+3 / 2$ \\
\hline \multicolumn{6}{|c|}{ IIIb } \\
\hline $\mathrm{N}(1)-\mathrm{H}(1 \mathrm{~A}) \cdots \mathrm{O}(4)$ & 0.75 & 2.00 & $2.748(3)$ & 171.3 & $x+1, y, z$ \\
\hline $\mathrm{N}(1)-\mathrm{H}(1 \mathrm{~B}) \cdots \mathrm{O}(6)$ & 0.75 & 2.08 & $2.811(3)$ & 167.0 & $x+1, y-1, z$ \\
\hline $\mathrm{N}(2)-\mathrm{H}(2 \mathrm{~A}) \cdots \mathrm{O}(3)$ & 0.74 & 2.07 & $2.796(3)$ & 165.7 & \\
\hline $\mathrm{N}(2)-\mathrm{H}(2 \mathrm{~B}) \cdots \mathrm{O}(1)$ & 0.74 & 2.04 & $2.758(3)$ & 164.6 & $x, y-1, z$ \\
\hline \multicolumn{6}{|c|}{ IIIc } \\
\hline $\mathrm{O}(5)-\mathrm{H}(5 \mathrm{~A}) \cdots \mathrm{O}(4)$ & $0.81(2)$ & $2.09(2)$ & $2.878(2)$ & $165(2)$ & $x+1, y, z$ \\
\hline $\mathrm{O}(5)-\mathrm{H}(5 \mathrm{~B}) \cdots \mathrm{O}(2)$ & $0.77(2)$ & $2.04(2)$ & $2.8140(19)$ & $176(2)$ & \\
\hline $\mathrm{N}(1)-\mathrm{H}(1 \mathrm{~A}) \cdots \mathrm{O}(1)$ & $0.92(2)$ & $1.84(2)$ & $2.7576(16)$ & $170.5(18)$ & $x+1 / 2,-y+1 / 2, z+1 / 2$ \\
\hline $\mathrm{N}(1)-\mathrm{H}(1 \mathrm{~B}) \cdots \mathrm{O}(3)$ & $0.88(2)$ & $1.92(2)$ & $2.7810(18)$ & $169.5(19)$ & $-x+1, y+1 / 2,-z+3 / 2$ \\
\hline $\mathrm{N}(2)-\mathrm{H}(2 \mathrm{~A}) \cdots \mathrm{O}(1)$ & $0.897(19)$ & $1.899(19)$ & $2.7711(15)$ & $163.5(19)$ & $-x+1, y+1 / 2,-z+3 / 2$ \\
\hline $\mathrm{N}(2)-\mathrm{H}(2 \mathrm{~B}) \cdots \mathrm{O}(3)$ & $0.89(2)$ & $1.86(2)$ & $2.7387(16)$ & $170.7(18)$ & \\
\hline \multicolumn{6}{|l|}{ पर } \\
\hline $\mathrm{O}(7)-\mathrm{H}(7 \mathrm{~B}) \cdots \mathrm{O}(5) \# 1$ & $0.76(2)$ & $1.95(2)$ & $2.7155(17)$ & $175(2)$ & $x-1, y, z$ \\
\hline $\mathrm{O}(7)-\mathrm{H}(7 \mathrm{~A}) \cdots \mathrm{O}(6)$ & $0.836(19)$ & $1.94(2)$ & $2.7664(17)$ & 168.7(19) & \\
\hline $\mathrm{N}(1)-\mathrm{H}(1 \mathrm{~A}) \cdots \mathrm{O}(3)$ & $0.882(18)$ & $1.960(18)$ & $2.8199(19)$ & $164.6(17)$ & \\
\hline $\mathrm{N}(1)-\mathrm{H}(1 \mathrm{~B}) \cdots \mathrm{O}(6) \# 2$ & $0.896(19)$ & $1.973(19)$ & $2.844(2)$ & $163.8(18)$ & $-x+2, y+1 / 2,-z+3 / 2$ \\
\hline $\mathrm{N}(1)-\mathrm{H}(1 \mathrm{~B}) \cdots \mathrm{O}(5) \# 2$ & $0.896(19)$ & $2.652(19)$ & $3.1863(19)$ & $119.2(14)$ & $-x+2, y+1 / 2,-z+3 / 2$ \\
\hline $\mathrm{N}(2)-\mathrm{H}(2 \mathrm{~B}) \cdots \mathrm{O}(4) \# 2$ & $0.881(19)$ & $1.829(19)$ & $2.7102(19)$ & $178.0(18)$ & $-x+2, y+1 / 2,-z+3 / 2$ \\
\hline $\mathrm{N}(2)-\mathrm{H}(2 \mathrm{~A}) \cdots \mathrm{O}(7) \# 3$ & $0.89(2)$ & $1.87(2)$ & $2.758(2)$ & $173.9(17)$ & $x+1 / 2,-y+1 / 2,-z+1$ \\
\hline
\end{tabular}

The assignment of bands in IR spectra was made taking into account the literature data [5-7, 13-15].

Free pyramidal $\mathrm{SO}_{3}^{2-}$ ion is known [15] to be related to $C_{3 v}$ point group and has four main vibration frequencies: $v_{1}\left(A_{1}\right)=967, v_{2}\left(A_{1}\right)=620, v_{3}(E)=933$; and $\mathrm{v}_{4}(E)=469 \mathrm{~cm}^{-1}$.

The IR spectrum of the mixture of compounds IIIa, IIIb, and IIIc show stretching vibrations $v(\mathrm{SO})$ of $\mathrm{SO}_{3}^{2-}$ ion ( $v_{1}$ and $v_{3}$, respectively) as strong absorption bands at 952 and $905 \mathrm{~cm}^{-1}$. This region also includes weaker bands at 1029, 1008, and $992 \mathrm{~cm}^{-1}$.
Two bands-medium intensity band at $492 \mathrm{~cm}^{-1}$ and a shoulder at $572 \mathrm{~cm}^{-1}$-can be considered as a result of splitting of doubly degenerated out-of-plane deformational vibration $\mathrm{v}_{4}(E)$ of ion $\mathrm{S}_{2} \mathrm{O}_{6}^{2-}$. Symmetrical deformational vibration $\delta_{\mathrm{s}}\left(\mathrm{SO}_{3}^{2-}\right)\left(v_{2}\right)$ of $\mathrm{SO}_{3}^{2-}$ ion appears as a medium intensity band at $620 \mathrm{~cm}^{-1}$.

Absorption bands with maxima at 3384 and $3247 \mathrm{~cm}^{-1}$ are related to asymmetrical and symmetrical $\mathrm{v}(\mathrm{N}-\mathrm{H})$ stretching vibrations, whereas lower frequency strong band at $3020 \mathrm{~cm}^{-1}$ can be assumingly assigned to vibrations with preferable contribution of $v\left(\mathrm{~N}^{+} \mathrm{H}\right)$. 


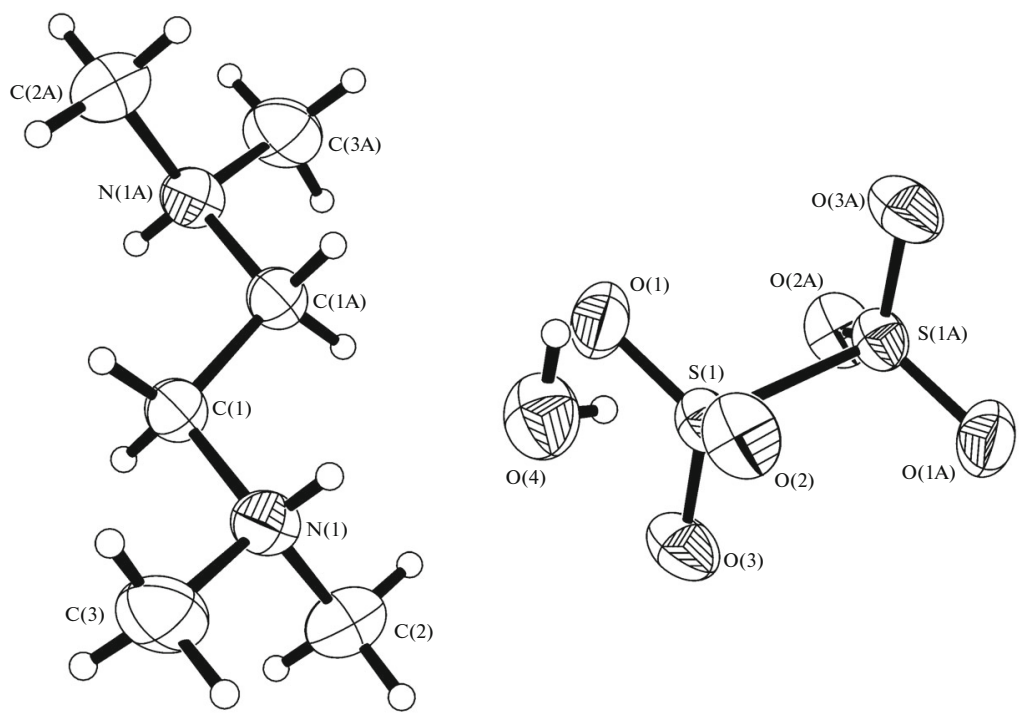

Fig. 1. Atom numbering scheme and thermal ellipsoids (probability level 50\%) for structure IIb. Letter A marks symmetrically equivalent atoms.
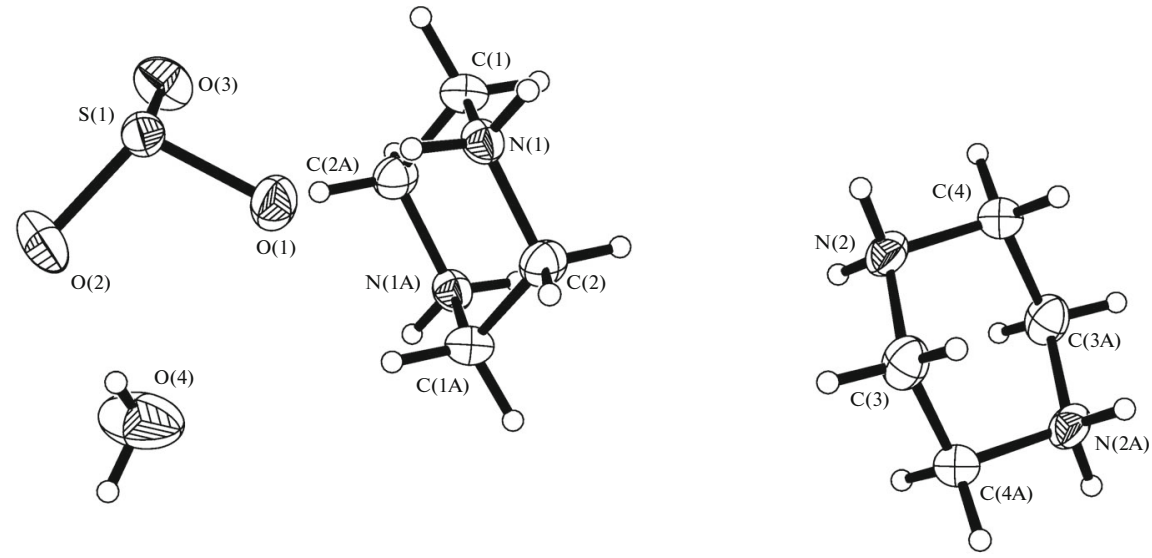

Fig. 2. Atom numbering scheme and thermal ellipsoids (probability level 50\%) for structure IIIa. Letter A marks symmetrically equivalent atoms.
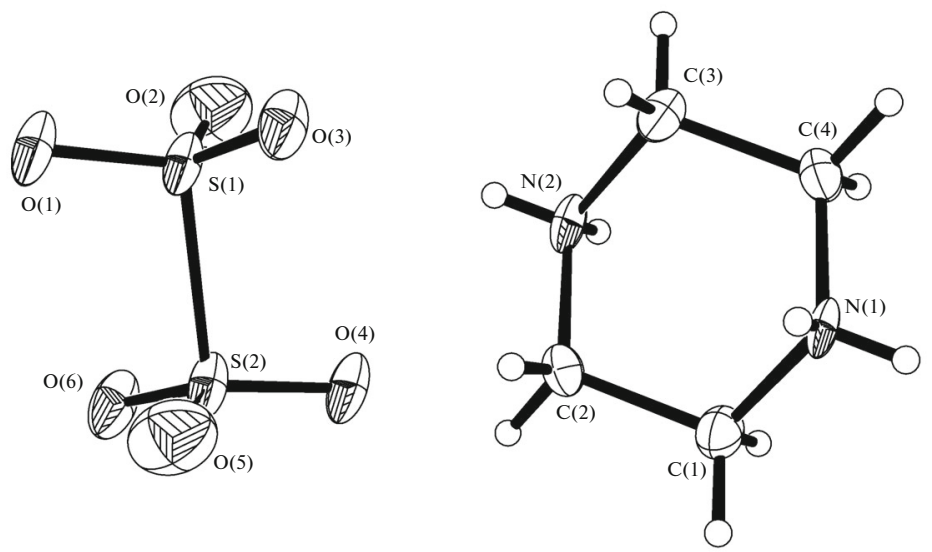

Fig. 3. Atom numbering scheme and thermal ellipsoids (probability level 50\%) for structure IIIb. 

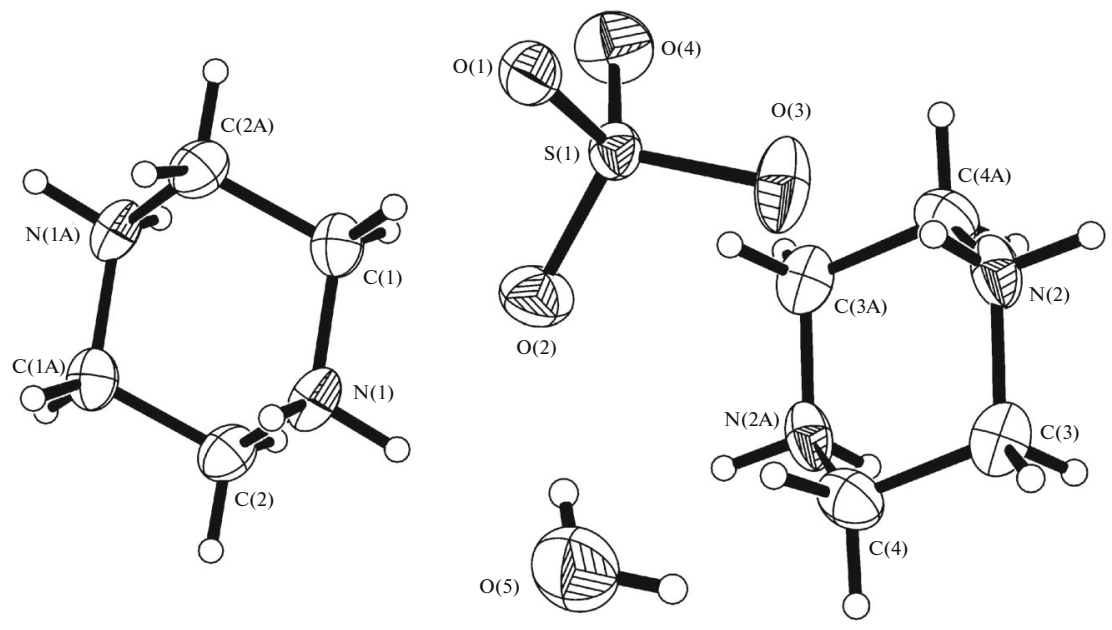

Fig. 4. Atom numbering scheme and thermal ellipsoids (probability level 50\%) for structure IIIc. Letter A marks symmetrically equivalent atoms.

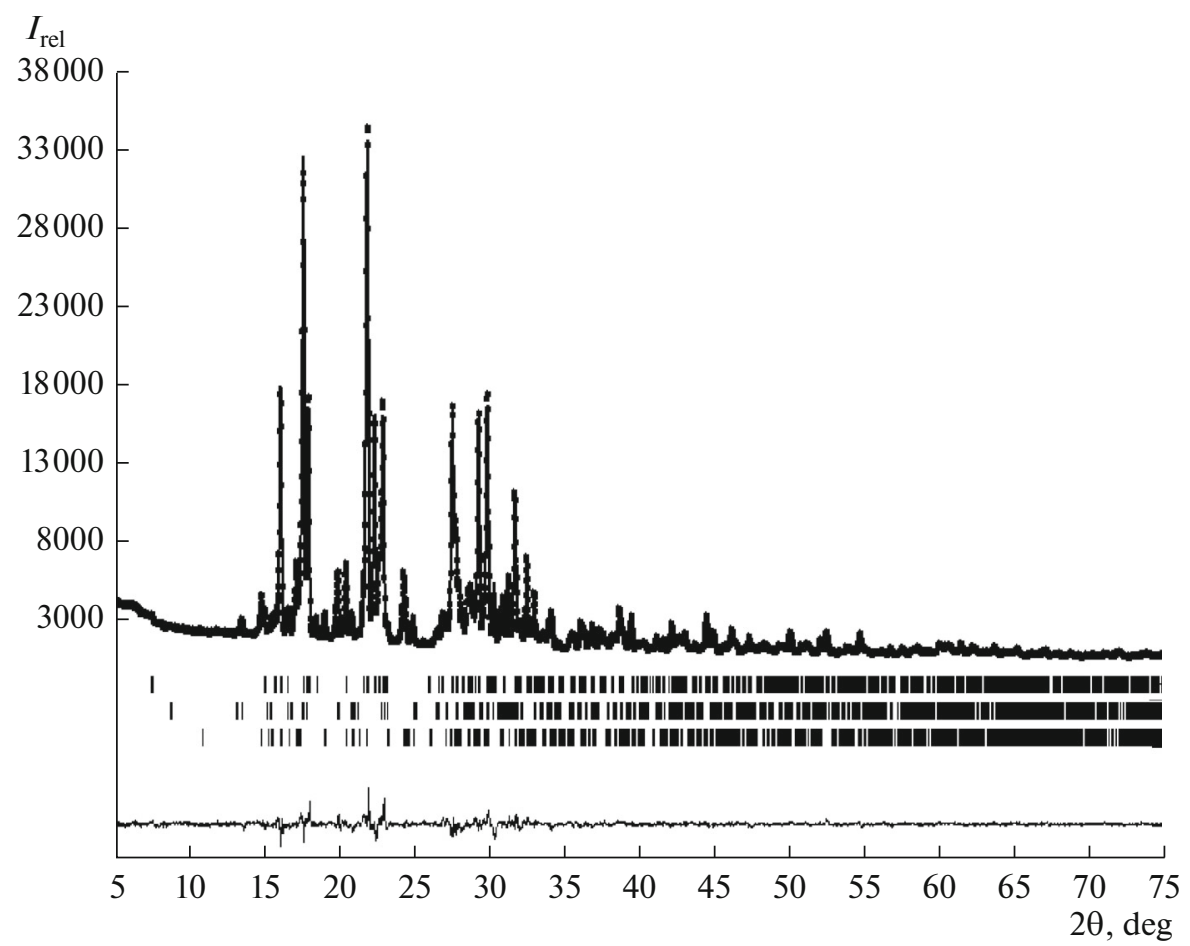

Fig. 5. Rietveld refinement for powder diffractogram of sample III. Dots show experimental curve, solid line displays calculation. Arrays of vertical dashes show diffraction maxima (upper row for IIIa, medium row for IIIb, lower row for IIIc). The lower curve displays the difference between experimental and calculated intensity values in each point.

The band at $1462 \mathrm{~cm}^{-1}$ may be assigned to mixed stretching deformational vibrations $v(\mathrm{CN})$ and $\delta(\mathrm{CNH})$. Deformational vibrations of $\mathrm{CH}_{2}$ group provide the main contribution to the bands at 1440 and $1380 \mathrm{~cm}^{-1}$. Medium intensity band at $1336 \mathrm{~cm}^{-1}$ and weak band at $1317 \mathrm{~cm}^{-1}$ correspond to asymmetrical and symmetrical $v(\mathrm{CN})$ vibrations, respectively.
The IR spectrum of compound I displays a strong band at $1111 \mathrm{~cm}^{-1}$ and very strong band at $1086 \mathrm{~cm}^{-1}$, corresponding to vibrations $\mathrm{v}_{\mathrm{as}}\left(\mathrm{SO}_{4}^{2-}\right)$ and $\mathrm{v}_{\mathrm{s}}\left(\mathrm{SO}_{4}^{2-}\right)$, respectively. Such a high intensity of band at $1086 \mathrm{~cm}^{-1}$ (the strongest band in the all spectrum) seems to be due to the contribution of $v\left(\mathrm{CN}^{+}\right)$vibrations of the ethylenediamine fragment. Decrease in the symmetry 


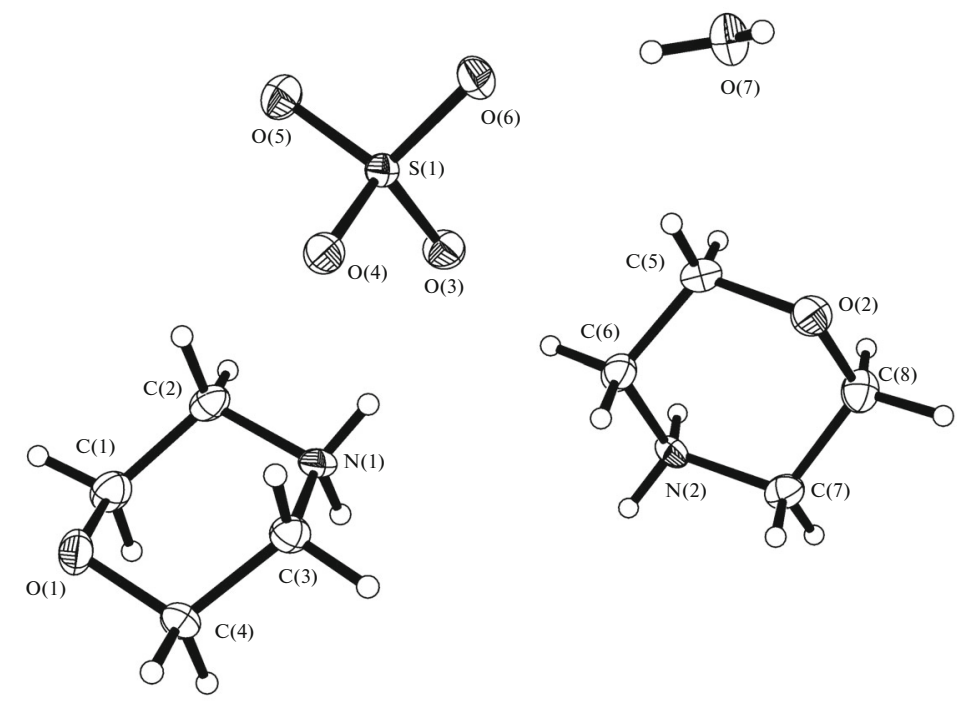

Fig. 6. Atom numbering scheme and thermal ellipsoids (probability level 50\%) for structure IV. Letter A marks symmetrically equivalent atoms.

of $\mathrm{SO}_{4}^{2-}$ ion upon complexation is accompanied by the emergence in IR spectrum of strong band of fully symmetric stretching vibration $v_{1}\left(A_{1}\right)$ at $989 \mathrm{~cm}^{-1}$. In similar manner, the strongest band in the spectrum of MP salt IV is a doublet at 1123 and $1105 \mathrm{~cm}^{-1}\left(\mathrm{v}_{\mathrm{as}}\left(\mathrm{SO}_{4}^{2-}\right)\right.$ and $\left.v_{\mathrm{s}}\left(\mathrm{SO}_{4}^{2-}\right)+\mathrm{v}\left(\mathrm{CN}^{+}\right)\right)$, while $\mathrm{v}_{1}\left(A_{1}\right)$ is observed as a medium intensity band at $997 \mathrm{~cm}^{-1}$. The strongest band in the spectrum of mixture of IIa and IIb is observed at $1122 \mathrm{~cm}^{-1}$, which seems to be the superposition of $v_{\text {as }}\left(\mathrm{SO}_{4}^{2-}\right)$ and $v\left(\mathrm{CN}^{+}\right)$vibrations of ethylenediamine fragment. Vibration $v_{1}\left(A_{1}\right)$ for this complex appears as a strong band at $998 \mathrm{~cm}^{-1}$.

The IR spectrum of the mixture of compounds IIIa, IIIb, and IIIc shows medium intensity bands at 1143 and $992 \mathrm{~cm}^{-1}$ corresponding to $\mathrm{v}_{\mathrm{as}}\left(\mathrm{SO}_{4}^{2-}\right)$ and $v_{\mathrm{s}}\left(\mathrm{SO}_{4}^{2-}\right)$ vibrations, respectively. A shoulder at $503 \mathrm{~cm}^{-1}$ refers to $\delta_{\mathrm{s}}\left(\mathrm{SO}_{4}^{2-}\right)$ deformational vibrations.

Three components of $v_{4}\left(\mathrm{SO}_{4}^{2-}\right)$ asymmetric deformational vibration appear in the IR spectrum of salt I as a strong doublet band with maxima at 639 and $609 \mathrm{~cm}^{-1}$ and medium intensity band at $672 \mathrm{~cm}^{-1}$, whereas only one strong band at $619 \mathrm{~cm}^{-1}$ is observed in the spectra of TMEDA and MP salts.

Three bands in the region $510-440 \mathrm{~cm}^{-1}$ typical for the frequencies of symmetrical deformational vibrations of $\mathrm{SO}_{4}^{2-}$ ion refer to EDA salt. On can suppose that band at $464 \mathrm{~cm}^{-1}$ has a contribution of deformational vibrations $\delta\left(\mathrm{N}^{+}-\mathrm{C}-\mathrm{C}-\mathrm{N}^{+}\right)$of the cation. Only medium intensity band at $518 \mathrm{~cm}^{-1}$ was revealed for the sample with TMEDA, while the spectrum of IV shows $\delta_{\mathrm{s}}\left(\mathrm{SO}_{4}^{2-}\right), v_{\mathrm{as}}\left(\mathrm{SO}_{4}^{2-}\right)$ and $v_{\mathrm{s}}\left(\mathrm{SO}_{4}^{2-}\right)$ bands similar to those of compound I.

Strong bands at 3013 and $2930 \mathrm{~cm}^{-1}$ in the spectrum of salt $\mathbf{I}$ correspond to stretching vibrations $v_{\text {as }}\left(\mathrm{NH}_{3}^{+}\right)$and $v_{\mathrm{s}}\left(\mathrm{NH}_{3}^{+}\right)$, respectively. Scissoring deformational vibrations of ammonium groups $\delta\left(\stackrel{H}{N}^{+} \mathrm{H}\right)$ and $\delta\left(\mathrm{C}^{\mathrm{N}} \mathrm{H}\right)$ are rather characteristic and appear as a doublet of strong bands at 1645 and $1631 \mathrm{~cm}^{-1}$. Even stronger band at $1537 \mathrm{~cm}^{-1}$ seems to correspond to $\delta_{\mathrm{s}}\left(\mathrm{NH}_{3}^{+}\right)$. Bands in the region $\sim 1560 \mathrm{~cm}^{-1}$ corresponding to deformational vibrations $\delta\left(\mathrm{NH}_{2}^{+}\right)$are present also in the spectra of complexes with piperazine and morpholine. This assignment is correct because of the lack of such a band in the spectrum of mixture of IIa with IIb where nitrogen in initial TMEDA is not hydrogenated. Bands in the region $\sim 1635-1630 \mathrm{~cm}^{-1}$ are present in the spectra of all prepared compounds.

The spectra of onium salts of TMEDA and PP display bands in the region $\sim 1210-1250 \mathrm{~cm}^{-1}$, which can be assigned to $v_{\mathrm{as}}\left(\mathrm{S}_{2} \mathrm{O}_{6}^{2-}\right)$, and bands at $\sim 580 \mathrm{~cm}^{-1}$ corresponding to $\delta\left(\mathrm{S}_{2} \mathrm{O}_{6}^{2-}\right)$. This fact confirms that the obtained compounds includes dithionate ions along with sulfate (IIa, IIIc) and sulfite (IIIa) anions. Moreover, a band of $\mathrm{v}_{\mathrm{s}}\left(\mathrm{S}_{2} \mathrm{O}_{6}^{2-}\right)$ at $1094 \mathrm{~cm}^{-1}$ is observed for PP sample.

We failed to perform correct identification of water absorption bands in IR spectra because of their overlapping with $v(\mathrm{NH})$ bands. 
Table 3. Wave numbers $\left(\mathrm{cm}^{-1}\right)$ for the maxima of the main absorption bands in IR spectra for the products of $\mathrm{SO}_{2}$ reaction with 1,2-diamines and morpholine

\begin{tabular}{|c|c|c|c|c|}
\hline & $\mathbf{I}$ & $\mathbf{I I a}+\mathbf{I I b}+\mathbf{I I c}$ & IIIa + IIIb + IIIC & IV \\
\hline$v_{\mathrm{as}}(\mathrm{NH})$ & & 3437 s br & $3388 \mathrm{~s}$ & $3418 \mathrm{~s}$ \\
\hline$v_{s}(\mathrm{NH})$ & & & $3252 \mathrm{~m}$ & $3286 \mathrm{~s}$ \\
\hline$v_{\mathrm{as}}\left(\mathrm{N}^{+} \mathrm{H}\right)$ & $3013 \mathrm{~s}$ & $3019 \mathrm{~s}$ & $3030 \mathrm{~s}$ & $3035 \mathrm{~s} \mathrm{br}$ \\
\hline$v_{\mathrm{s}}\left(\mathrm{N}^{+} \mathrm{H}\right)$ & $2930 \mathrm{~s}$ & $2623 \mathrm{~s}$ & $2616 \mathrm{w}$ & $2627 \mathrm{~m}$ \\
\hline$\delta\left(\mathrm{HN}^{+} \mathrm{H}\right)$ & $1645 \mathrm{~s}$ & & & \\
\hline$\delta\left(\mathrm{CN}^{+} \mathrm{H}\right)$ & $1631 \mathrm{~s}$ & $1635 \mathrm{~m} \mathrm{br}$ & $1631 \mathrm{~m}$ & $1634 \mathrm{~m}$ \\
\hline$\delta_{\mathrm{as}}(\mathrm{CNH})$ & & & $1492 \mathrm{w}$ & \\
\hline$v(\mathrm{CN})+\delta(\mathrm{CNH})$ & & & $1462 \mathrm{~m}$ & $1464 \mathrm{w}$ \\
\hline$\delta_{\mathrm{s}}\left(\mathrm{NH}_{3}^{+}\right), \delta\left(\mathrm{NH}_{2}^{+}\right)$ & $1537 \mathrm{~s}$ & & $1560 \mathrm{w}$ & $1561 \mathrm{~s}$ \\
\hline$v_{\text {as }}(\mathrm{CN})$ & & & $1335 \mathrm{~m}$ & \\
\hline$v_{s}(\mathrm{CN})$ & & & $1317 \mathrm{w}$ & $\begin{array}{l}1308 \mathrm{~m}, 1243 \mathrm{w}, \\
1227 \mathrm{~m}\end{array}$ \\
\hline$v_{\mathrm{as}}\left(\mathrm{S}_{2} \mathrm{O}_{6}^{2-}\right)$ & & $1240 \mathrm{~m}, 1214 \mathrm{w}$ & $1240 \mathrm{w}, 1216 \mathrm{w}$ & \\
\hline $\mathrm{v}_{\mathrm{s}}\left(\mathrm{S}_{2} \mathrm{O}_{6}^{2-}\right)$ & & & $1094 \mathrm{~m}$ & \\
\hline$v_{\text {as }}\left(\mathrm{SO}_{4}^{2-}\right)$ & $1111 \mathrm{~s}$ & & $1143 \mathrm{~m}$ & 1123 vs \\
\hline$v_{\mathrm{as}}\left(\mathrm{SO}_{4}^{2-}\right)+\mathrm{v}\left(\mathrm{CN}^{+}\right)$ & 1086 vs & 1122 vs & $1105 \mathrm{~m}$ & 1105 vs \\
\hline$v_{\mathrm{as}}+\mathrm{v}_{\mathrm{s}}\left(\mathrm{SO}_{3}^{2-}\right)$ & & & $\begin{array}{l}1029 \mathrm{~m}, 1008 \mathrm{w}, \\
992 \mathrm{w}, 952 \mathrm{~s}, 905 \mathrm{~s}\end{array}$ & \\
\hline$v_{\mathrm{s}}\left(\mathrm{SO}_{4}^{2-}\right)$ & $989 \mathrm{~s}$ & $998 \mathrm{~s}$ & $992 \mathrm{~m}$ & $997 \mathrm{~m}$ \\
\hline$\delta_{\mathrm{as}}\left(\mathrm{SO}_{4}^{2-}\right)$ & $672 \mathrm{~m}, 639 \mathrm{~s}, 609 \mathrm{~s}$ & $619 \mathrm{~s}$ & $620 \mathrm{~m}$ & 619 vs \\
\hline$\delta_{\mathrm{s}}\left(\mathrm{SO}_{3}^{2-}\right)$ & & & & \\
\hline$\delta\left(\mathrm{S}_{2} \mathrm{O}_{6}^{2-}\right)$ & & $582 \mathrm{~m}$ & $572 \mathrm{sh}$ & \\
\hline$\delta_{\mathrm{s}}\left(\mathrm{SO}_{4}^{2-}\right)$ & $511 \mathrm{~m}, 442 \mathrm{~m}$ & $518 \mathrm{~m}$ & $503 \mathrm{sh}$ & $518 \mathrm{w}, 438 \mathrm{~s}$ \\
\hline$\delta_{\mathrm{d}}\left(\mathrm{SO}_{3}^{2-}\right)$ & & & $492 \mathrm{~m}$ & \\
\hline$\delta_{\mathrm{s}}\left(\mathrm{SO}_{4}^{2-}\right)+\delta\left(\mathrm{N}^{+}-\mathrm{C}-\mathrm{C}-\mathrm{N}^{+}\right)$ & $464 \mathrm{~m}$ & & $470 \mathrm{w}$ & \\
\hline
\end{tabular}

It should be noted that PP under similar synthesis conditions [16] (reaction mixture $\mathrm{pH} \mathrm{PP}: \mathrm{SO}_{2}=3: 2$ ). A white onium sulfite was isolated in $\mathrm{SO}_{2}-\mathrm{EDA}-\mathrm{Sol}$ system ( Sol is absolute ethanol, aqueous ethanol, or acetone) [17].

On the basis of above results, the data of our previous studies of $\mathrm{SO}_{2}-\mathrm{L}-\mathrm{H}_{2} \mathrm{O}$ ( $\mathrm{L}$ stands for alkylmonoamines) [18-21], and literature data, we can draw the following conclusion.

As shown in [22], sulfur(IV) oxide upon dissolution in water produces monohydrate (equation (1)), which dissociate to form hydrogen sulfite, pyrosulfite, and sulfite ions (equations (2)-(4)):

$$
\begin{gathered}
\mathrm{SO}_{2}+\mathrm{H}_{2} \mathrm{O} \rightarrow \mathrm{SO}_{2} \cdot \mathrm{H}_{2} \mathrm{O}, \\
\mathrm{SO}_{2} \cdot \mathrm{H}_{2} \mathrm{O} \stackrel{K_{1}}{\rightleftarrows} \mathrm{H}^{+}+\mathrm{HSO}_{3}^{-}, \\
2 \mathrm{HSO}_{3}^{-} \stackrel{K^{\cdot}}{\rightleftarrows} \mathrm{S}_{2} \mathrm{O}_{5}^{2-}+\mathrm{H}_{2} \mathrm{O}, \\
\mathrm{HSO}_{3}^{-} \stackrel{K_{2}}{\rightleftarrows} \mathrm{H}^{+}+\mathrm{SO}_{3}^{2-}
\end{gathered}
$$

According to the mechanism of free-radical oxidation of sulfite ion $[23,24]$, chain initiation proceeds due to decomposition of pyrosulfite ion: 


$$
\mathrm{S}_{2} \mathrm{O}_{5}^{2-} \rightleftarrows \mathrm{SO}_{3}^{\cdot-}+\mathrm{SO}_{2}^{--}
$$

or via reaction of $\mathrm{SO}_{3}^{2-}$ ion with small amount of admixture metal ions of variable valence always present also in distilled water:

$$
\mathrm{SO}_{3}^{2-}+\mathrm{M}^{n+} \rightleftarrows \mathrm{SO}_{3}^{--}+\mathrm{M}^{(n-1)+}
$$

Furthermore [25], $\mathrm{SO}_{2}$ forms with organic nitrogen-containing bases (with MP, in particular) chargetransfer complexes, which also behave as sources of free radicals:

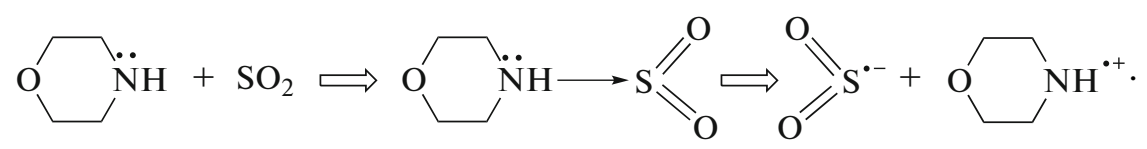

Chain propagation proceeds according to equations (8)-(15) [24]. In the systems producing onium dithionates, chain termination occurs by reaction (16). The lack of pyrosulfites in preparatively isolated products indicates the occurrence of reaction (17) [24]:

$$
\begin{aligned}
& \mathrm{SO}_{3}^{--}+\mathrm{O}_{2} \rightarrow \mathrm{SO}_{5}^{\cdot-} \quad 2.5 \times 10^{9}, \\
& \mathrm{SO}_{5}^{--}+\mathrm{HSO}_{3}^{-} \rightarrow \mathrm{HSO}_{5}^{-}+\mathrm{SO}_{3}^{--}(3.4-8.6) \times 10^{2},(9) \\
& \mathrm{SO}_{5}^{--}+\mathrm{HSO}_{3}^{-} \\
& \rightarrow \mathrm{SO}_{4}^{2-}+\mathrm{SO}_{4}^{--}+\mathrm{H}^{+} \leq(2-3.6) \times 10^{2}, \\
& \mathrm{SO}_{5}^{--}+\mathrm{SO}_{3}^{2-} \rightarrow \mathrm{SO}_{5}^{2-}+\mathrm{SO}_{3}^{--} 2.1 \times 10^{5}, \\
& \mathrm{SO}_{5}^{--}+\mathrm{SO}_{3}^{2-} \rightarrow \mathrm{SO}_{4}^{2-}+\mathrm{SO}_{4}^{--} 5.5 \times 10^{5} \text {, } \\
& \mathrm{SO}_{4}^{--}+\mathrm{HSO}_{3}^{-} \\
& \rightarrow \mathrm{SO}_{4}^{2-}+\mathrm{SO}_{3}^{--}+\mathrm{H}^{+}(6.8-7.5) \times 10^{8}, \\
& \mathrm{SO}_{4}^{--}+\mathrm{SO}_{3}^{2-} \rightarrow \mathrm{SO}_{4}^{2-}+\mathrm{SO}_{3}^{--}(3.1-5.7) \times 10^{8} \\
& \mathrm{SO}_{5}^{--}+\mathrm{SO}_{5}^{--} \rightarrow \mathrm{SO}_{4}^{--}+\mathrm{SO}_{4}^{--}+\mathrm{O}_{2}(8.7-22) \times 10^{7} \text {, (15) } \\
& \mathrm{SO}_{3}^{--}+\mathrm{SO}_{3}^{--} \rightarrow \mathrm{S}_{2} \mathrm{O}_{6}^{2-} \text {, } \\
& \mathrm{HSO}_{5}^{-}+\mathrm{HSO}_{3}^{-}+\mathrm{H}^{+} \\
& \rightarrow 2 \mathrm{SO}_{4}^{2-}+3 \mathrm{H}^{+} \approx 10^{7}\left[\mathrm{H}^{+}\right] \text {. }
\end{aligned}
$$

The isolation of sulfates I, IIa, IIIc, and IV, as well as the results [18-21], indicates the presence of reactions (10), (13), (14), and (17); the isolation of dithionates IIb and IIIb as mixtures evidences the occurrence of reaction (16).

We previously [27-30] isolated onium sulfites from $\mathrm{SO}_{2}-\mathrm{L}-\mathrm{H}_{2} \mathrm{O}$ systems ( $\mathrm{L}$ is ethanolamine, aminoguanidine) under similar conditions because alkanols inhibit sulfooxidation [31-33]. In the case of TRIS, onium sulfate forms under similar conditions [19]. In contrast to the results [27], diethanolamine accelerates S(IV) oxidation, while triethanolamine is inert [34].

The established fact that EDA and MEA additives partially suppress the catalytic oxidation of sodium sulfite under the action of $3 d$ metal cations $\left(\mathrm{Mn}^{2+}\right.$, $\mathrm{Fe}^{2+}$, and $\mathrm{Cu}^{2+}$ ) [32] seems to indicate that the forma- tion of free radicals via reaction (6) in the studies systems is unlikely.

The possibility to realize the process of mild $\mathrm{SO}_{2}$ oxidation under reported synthesis conditions using a wider series of amine ligands will be elucidated in further studies.

\section{REFERENCES}

1. K. Eller, E. Henkes, R. Rossbacher, and H. Hoke, Ullmann's Encyclopedia of Industrial Chemistry (WileyVCH, Weinheim, 2005), Vol. 2, p. 647. doi 10.1002/14356007.a02_001

2. K. Jayaraman, A. Choudhury, and C. N. R. Rao, Solid State Sci. 4, 413 (2002). doi 10.1016/S12932558(02)01269-4

3. L. A. Cuccia, L. Koby, J. B. Ningappa, and M. Dakessian, J. Chem. Educ. 82, 1043 (2005). doi 10.1021/ed082p 1043

4. N. C. Santhakumari and C. P. G. Vallabhan, J. Phys. Chem. Solids 53, 697 (1992). doi 10.1016/00223697(92)90210-5

5. J. Bellanato, Spectrochim. Acta 16, 1344 (1960). doi 10.1016/S0371-1951(60)80008-2

6. M. K. Marchewka and M. Drozd, Spectrochim. Acta, Part A Mol. Biomol. Spectrosc. 99, 223 (2012). doi 10.1016/j.saa.2012.09.026

7. B. R. Srinivasan, S. S. Khandolkar, R. N. Jyai, et al., Spectrochim. Acta, Part A Mol. Biomol. Spectrosc. 102, 235 (2013). doi 10.1016/j.saa.2012.09.103

8. B. M. Yamin, L. Narimani, and N. Ibrahim, Int. J. Adv. Sci., Eng. Inf. Technol. 3 (2), 47 (2013).

9. V. A. Klimova, The Main Methods for Analysis of Organic Compounds (Khimiya, Moscow, 1975) [in Russian].

10. G. M. Sheldrick, Acta Crystallogr., Sect. A: Found. Crystallogr. 64, 112 (2008). doi 10.1107/ S0108767307043930

11. N. S. Vul'fson, V. G. Zaikin, and A. I. Mikaya, Mass Spectrometry of Organic Compounds (Khimiya, Moscow, 1986).

12. T. Guerfel, A. Gharbi, and A. Jouini, J. Soc. Alger. Chim. 2, 125 (2007).

13. S. Gunasekaran and B. Anita, Ind. J. Pure Appl. Phys. 46, 833 (2008). 
14. R. A. Nyquist and R. O. Kagel, Handbook of Infrared and Raman Spectra of Inorganic Compounds and Organic Salts (Academic, New York, 1996), Vol. 4.

15. K. Nakamoto, Infrared and Raman Spectra of Inorganic and Coordination Compounds (Interscience, New York, 1986).

16. US Patent No. 3046277 (1962).

17. US Patent No. 2069165 (1937).

18. R. E. Khoma, A. A. Ennan, O. V. Shishkin, et al., Russ. J. Inorg. Chem. 57, 1559 (2012). doi 10.1134/ S003602361212008X

19. R. E. Khoma, V. O. Gel'mbol'dt, O. V. Shishkin, et al., Russ. J. Inorg. Chem. 59, 1 (2014). doi 10.1134/ S0036023614010069

20. R. E. Khoma, A. A. Ennan, V. O. Gelmboldt, et al., Russ. J. Gen. Chem. 84, 637 (2014). doi 10.1134/ S1070363214040069

21. R. E. Khoma, V. O. Gel'mbol'dt, V. N. Baumer, et al., Russ. J. Inorg. Chem. 60, 1199 (2015). doi 10.1134/ S0036023615100101

22. S. Pereda, K. Thomsen, and P. Rasmussen, Chem. Eng. Sci. 55, 2663 (2000). doi 10.1016/S00092509(99)00535-7

23. S. K. Fedorova, I. P. Skibida, and A. V. Gladkii, Zh. Prikl. Khim. 50, 716 (1976).

24. A. N. Ermakov and A. P. Purmal', Kinet. Catal. 42, 479 (2001). doi 10.1023/A:1010565304435
25. P. Ghosh and G. Pal, J. Polym. Sci., Part A: Polym. Chem. 36, 1973 (1998). doi 10.1002/(SICI)10990518(19980915)36:12<1973::AID-POLA1>3.0.CO;2-P

26. G. Qing-yu, L. Run-ming, Y. Geng-xu, et al., Imag. Sci. Photochem. 19, 116 (2001). doi 10.7517/j.issn. 1674-0475.2001.02.116

27. R. E. Khoma, V. O. Gel'mbol'dt, L. V. Koroeva, et al., Vopr. Khim. Khim. Tekhnol., No. 1, 133 (2012).

28. R. E. Khoma, A. A. Ennan, A. V. Mazepa, and V. O. Gel'mbol'dt, Vopr. Khim. Khim. Tekhnol., No. 1, 136 (2013).

29. R. E. Khoma, V. O. Gelmboldt, O. V. Shishkin, et al., Russ. J. Inorg. Chem. 84, 541 (2014). doi 10.1134/ S0036023614060096

30. R. E. Khoma, V. O. Gelmboldt, V. N. Baumer, et al., Russ. J. Inorg. Chem. 58, 843 (2013). DOI: doi 10.1134/S0036023613070140

31. U. Deister and P. Warnek, J. Phys. Chem. 94, 2191 (1990). doi 10.1021/j100368a084

32. J. Ziajka and W. Pasiuk-Bronikowska, Atmos. Environ. 37, 3913 (2003). doi 10.3109/10715769309056520

33. US Patent No. 213032 (1938).

34. US Patent No. 4310438 (1982).

Translated by I. Kudryavtsev 